\title{
A Imprensa vaì̀ Guerra do Paraguai. \\ o uso da caricatura como arma de guerra no século XIX
}

Edgley Pereira de Paula*

O presente artigo pretende problematizar o papel da imprensa brasileira e paraguaia como parte integrante do esforço empreendido pelos dois países envolvidos no grande conflito bélico que envolveu as nações platinas no período entre 1864 e 1870 , partindo da perspectiva de se pensar as imagens impressas produzidas nos periódicos que retratavam a guerra.

Palavras-chave: imprensa, guerra, caricaturas

The present article intends to reflect about the paper of the Brazilian and Paraguayan press as integrant part of the effort undertaken for the two involved countries in the great war conflict that involved the platinum nations in the period between 1864 and 1870, starting from a perspective of thinking the images produced in the periodic that portrayed the war.

Key words: press, war, caricature.
U oje em dia, não raro, nos depa1 ramos com jornais e revistas multicoloridos, sedutores, com grande quantidade de imagens que auxiliam o entendimento do texto e por vezes torna a leitura mero meio auxiliar, pois, na verdade, a imagem já disse tudo...

Essa capacidade que a imagem possui foi largamente utilizada durante o grande conflito armado que marcou a construção das identidades dos povos do atual Mercosul.

Porém nem sempre foi assim, a tecnologia para se imprimir imagens

\footnotetext{
* O Autor é Oficial do Exército Brasileiro do Quadro Complementar (Historiador), possui Bacharelado e Licenciatura Plena em História pela Universidade do Estado do Rio de Janeiro (UERJ), Pós-graduação em História Militar Brasileira pela Universidade Federal do Estado do Rio de Janeiro (UNIRIO) e Mestrado em História Política no Programa de Pós-Graduação em História (PPGH/ UERJ), sócio honorário do Instituto de Geografia e História Militar do Brasil (IGHMB), sócio ti-
} 
em papel levou muitos anos, até o ponto de se baratear e tornar possível sua reprodução em maior escala, para depois ser utilizada nos jornais que circularam particularmente no Brasil, na corte do Rio de Janeiro e no Paraguai no período da Guerra da Tríplice Aliança (1864 - 1870).

O assunto guerra, por ser de valor capital, ponto de inflexão de toda sociedade, geralmente conta com uma considerável produção de documentos, de fontes que envolvem tal fato histórico, contudo, em nenhum outro tema de pesquisa, opiniões são tão diversas, tão apaixonadas e tão discrepantes sobre o mesmo assunto, principalmente quando analisamos documentos produzidos nos países contendores.

O conflito armado geralmente é estudado dissociado de seus múltiplos aspectos econômicos, sociais e mais ainda culturais, privilegiado análises políticas, diplomáticas ou puramente de caráter militar, a dita "História Batalha", esvaziando as possíveis discussões mais aprofundadas do acontecimento "guerra" para se entender a história das sociedades.

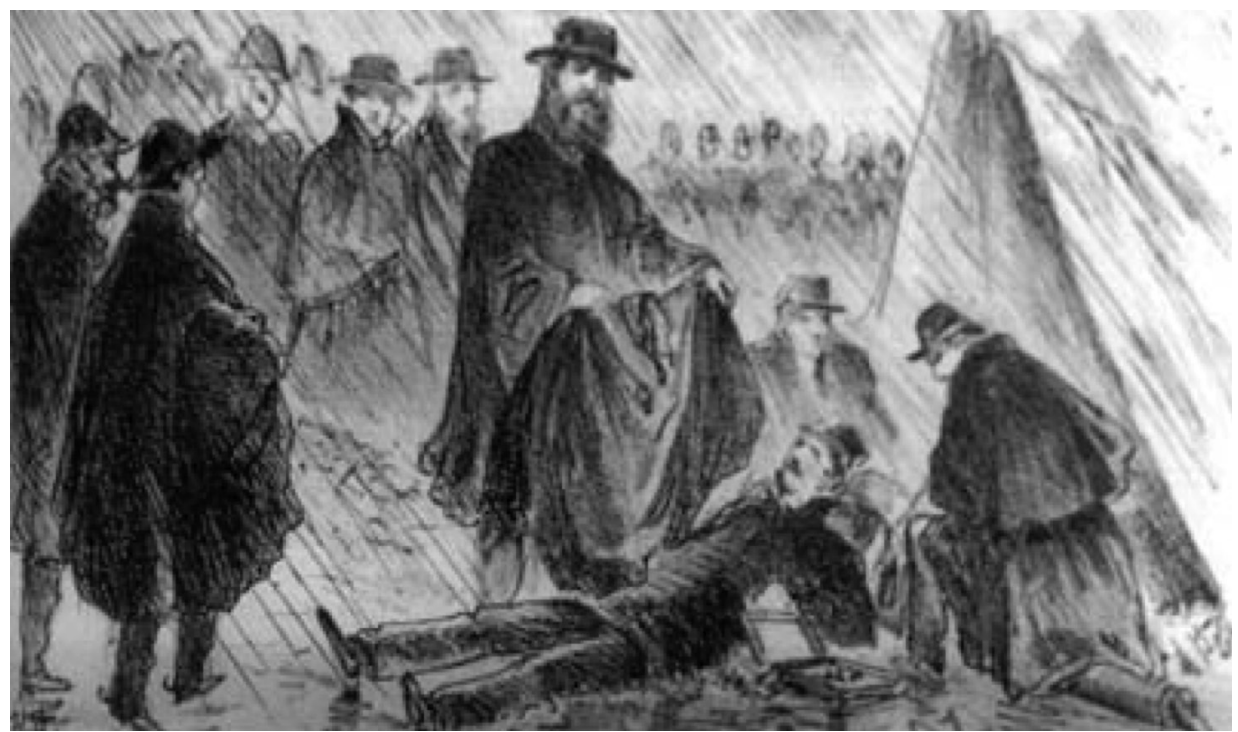

Figura 1 - O imperador como $1^{\circ}$ Voluntário da Pátria em Uruguaiana - Semana Illustrada - 1865

tular da Academia de História Militar Terrestre do Brasil (AHMTB), Seção Brasília e pesquisador do Centro de Estudos e Pesquisas em História Militar do Exército (CEPHiMEx). Ex-professor do Colégio Militar de Brasília, atualmente serve na Diretoria do Patrimônio Histórico e Cultural do Exército (DPHCEx).edgleydepaula@hotmail.com 
Ao longo do século XIX, o acesso à imagem vai paulatinamente se difundindo. Obras de arte, quadros e pinturas que se encontravam nas mansões, em livrarias, nas confrarias reservadas para uma pequena elite aos poucos vai se ampliando e complexificando seu acesso, assim como, os espaços públicos.

Nesse contexto, as publicações ilustradas impressas e os jornais que proliferaram, particularmente, depois do início da guerra (1864), divulgadas quase que diariamente nos diferentes jornais, causaram forte impacto, não só na sociedade como também nos homens que estavam sendo arregimentados e enviados para lutarem nas campanhas militares no Paraguai.

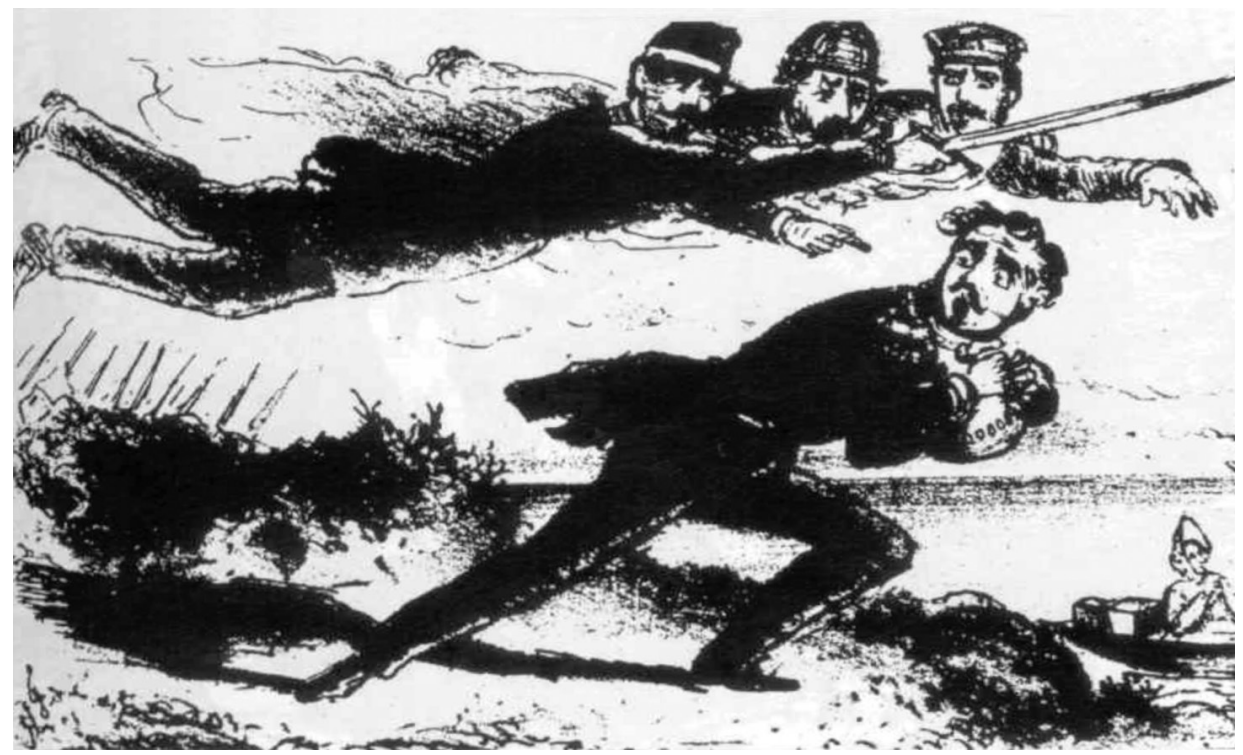

Figura 2 - Solano López sendo acossado pela Tríplice Aliança - Semana Illustrada - 1865.

As representações construídas na guerra, possivelmente, não teriam prosperado sem a participação das imagens que circularam na imprensa em charges e caricaturas. A irreverência foi a chave utilizada, tanto pelo lado paraguaio, quanto pelo brasileiro, para retratar o inimigo a ser vencido, mas, por trás dessa crítica despudorada evidenciava-se uma gama de preconceitos existentes e que estavam sendo construídos e massificados entre as nações em conflito. 


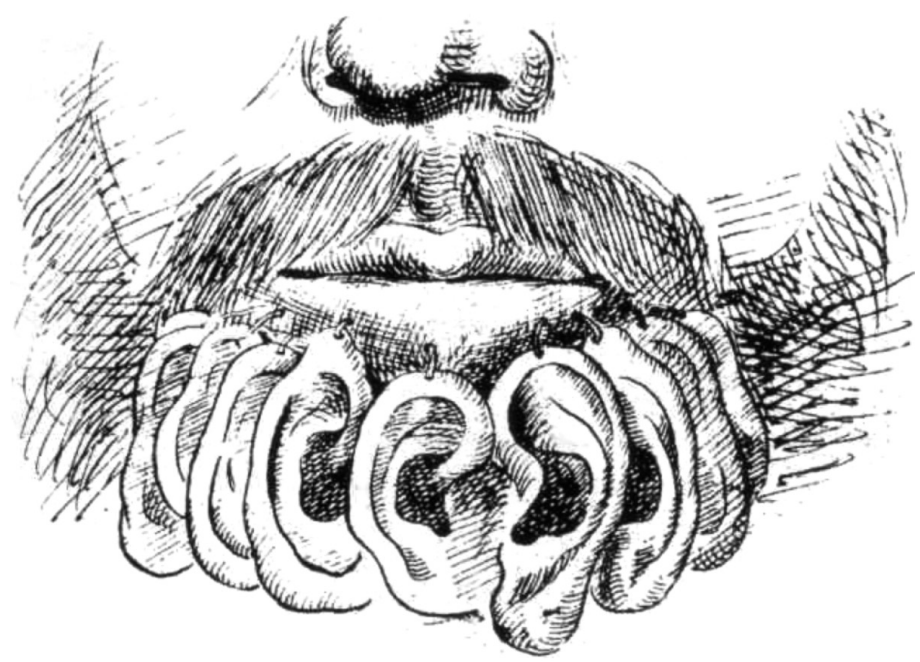

Figura 3 - A crueldade e selvageria dos paraguaios sendo retratada nos periódicos brasileiros - Paraguay Illustrado - 1865

Ao transpor para o papel a imagem do "outro", os periódicos validaram e desmascararam, através de instrumentos de corrosão da imagem do inimigo, juízo de valores já preexistentes no imaginário coletivo daquelas populações.

Dentre outros periódicos de época que retrataram o conflito temos: A Semana Illustrada, que circulou durante todo o conflito bélico; o Paraguay Illustrado, periódico especializado em cobrir a guerra em andamento e que teve vida efêmera - de julho a outubro de 1865, efetivamente no primeiro ano da guerra e que apesar de curta duração, produziu uma considerável quantidade de imagens e o Bazar Volante, periódico que durante o decorrer do conflito mudará de nome por duas vezes, em 1867 passará a se chamar O Arlequim e a partir de 1868, Vida Fluminense, isso do lado brasileiro, todos em circulação na corte do Rio de Janeiro, então capital do Império.

Do lado paraguaio dois principais jornais: o Cabichuí, editado na frente de combate em Paso Pocú entre maio de 1867 e agosto de 1868 e o El Centinela, editado em Assunção desde 1865 até 1868.

O interessante é que ao observarmos a imagem como representação do inimigo a ser derrotado percebemos não apenas o discurso de quem produziu as caricaturas, mas, também de quem as viu e como as viu. 


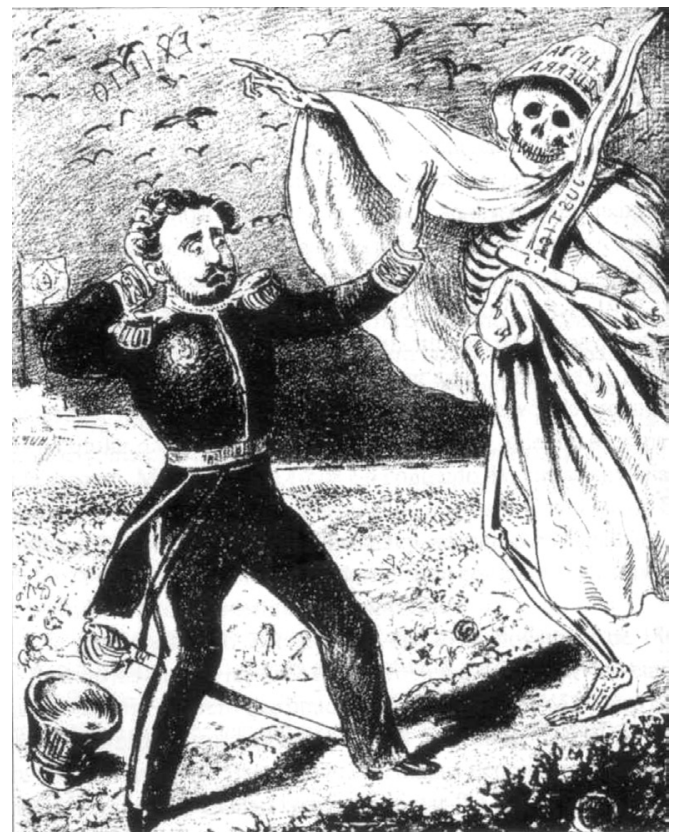

Figura 4 - A espada civilizadora da Tríplice Aliança - Semana Illustrada - 1867

As representações, segundo o historiador francês Roger Chartier, inserem-se "em um campo de concorrências e de competições cujos desafios se enunciam em termos de poder e de dominação" "; em outras palavras, são produzidas aqui verdadeiras "lutas de representações".

E estas lutas geram inúmeras "apropriações" de acordo com os interesses sociais, com as imposições e resistências políticas, com as motivações e necessidades que se confrontam no mundo humano.

Nesse sentido, o relato de um oficial subalterno do exército imperial chamado Dionísio Cerqueira sobre a utilização dessas imagens como armas de guerra faz-se revelador:

Para exaltar o espírito dos seus soldados, cuja valentia, obediência e abnegação dispensavam aliás estímulos. López nos mandava injuriar pela sua imprensa. (...) Às vezes, sem sabermos como, apareciam exemplares, cobertos de injúrias

${ }^{1}$ CHARTIER, Roger. A História Cultural: entre práticas e representações. Lisboa: Difel; Rio de Janeiro: Editora Bertrand Brasil, 1990. p. 17. 
aos aliados, nos nossos acampamentos. De alguns sabíamos a origem: eram encontrados nos bolsos dos mortos e feridos. Os outros haviam sido deixados provavelmente pelos espiões, que não eram raros e passavam facilmente por orientais no acampamento argentino, por argentinos no oriental e por orientais ou argentinos no brasileiro. ${ }^{2}$

No Brasil, de uma maneira geral, as imagens personificaram a figura de López, como o grande causador da guerra e por isso ela só poderia terminar quando da eliminação do seu causador.

O Paraguai era retratado como uma nação longínqua, isolada e sob o poder tirânico de um ditador, já o Império e seus aliados teriam essa missão civilizadora e libertadora a cumprir, muito bem alinhado com o discurso reinante à época, do "fardo civilizatório" que as nações mais desenvolvidas teriam para com as mais "bárbaras"; deve-se lembrar que o modelo de civilização moderna e avançada à época era a Inglaterra Vitoriana com sua secular monarquia.

A selvageria e crueldade de Solano López foi tema recorrente durante todo o conflito expostas nos diferentes periódicos. Porém, de acordo com o passar dos anos, as resistências e as sucessivas fugas do Mariscal e seus últimos homens vai desgastando a imagem do exército imperial.

O medo da fuga de López rumo à Europa aparece recorrente nas caricaturas, ora como ave de rapina, levando polpudos sacos de dinheiro, ora como demônio à atiçar nosso imaginário cristão.

Aliás, é interessante verificar que tanto nas caricaturas brasileiras quanto nas paraguaias a alusão, seja no estilo, seja através de metáforas, com a passagem do apocalipse da Bíblia Paulina é recorrente, no caso, o Apocalipse: a morte, a fome, a peste, a guerra, ora López como anti-Cristo, ora Dom Pedro II; o que demonstra que as chaves de leituras eram muito próximas...

O fator "tempo" evidenciará, de uma maneira geral, as diferentes vertentes dos periódicos da corte carioca, o ufanista Paraguay Illustrado resistirá apenas alguns meses de 1865, o Bazar Volante, O Arlequim e a A Vida Fluminense seguirão uma linha mais crítica do conflito, enquanto que a Semana Illustrada, de uma maneira geral continuará alinhada ao discurso do império.

\footnotetext{
${ }^{2}$ CERQUEIRA, Dionísio. Reminiscências da campanha do Paraguai, 1865-1870. Rio de Janeiro, Biblioteca do Exército Editora, 1980, p.121/122.
} 
Contudo, com o passar dos anos, pátria e governo vão se diferenciando nos desenhos produzidos. Nas publicações brasileiras, o Brasil passa a ser retratado como um índio ora normal, ora gigante, ou então, comumente doente ou acamado, com o imperador e ministros receitando remédios duvidosos. O país, nesse caso, era mostrado como entidade independente do governo.

No Paraguai, as imagens se concentraram tanto no chefe de estado brasileiro, o imperador D. Pedro II, quanto no povo brasileiro, ao ridicularizar a tropa brasileira como um exército de negros macacos, incapazes de lutarem tão valorosamente quanto o combatente guarani.

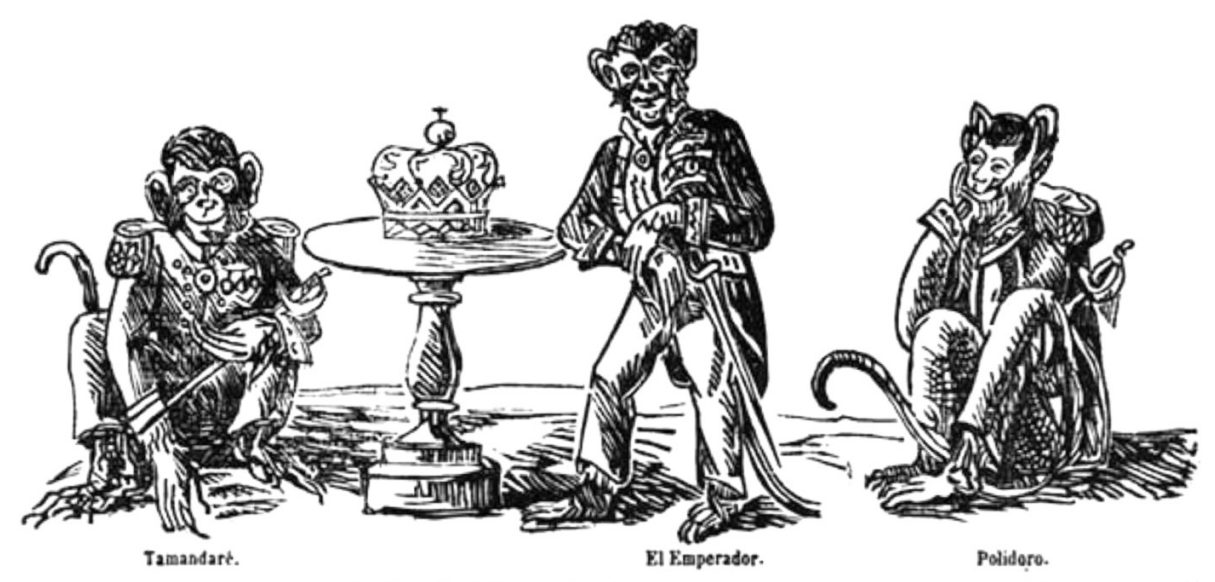

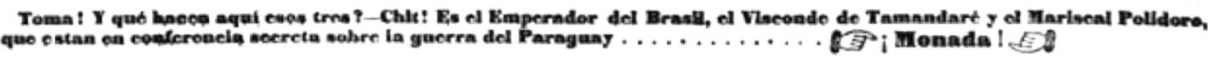

Figura 5 - O imperador, o almirante Tamandaré e o General Polidoro como macacos - El Centinela - 1867

A atitude jocosa perante os nossos chefes militares também será recorrente: D. Pedro II era "Macacon", Porto Alegre virava "Porto Triste"; General Osório, conhecido por "Osário"; e o Duque de Caxias "el gran jefe Macacuno". Também será alvo de piadas a pontaria da esquadra brasileira:

El Cabichuí considerando la conveniência de llamar-se lãs casas de la Guerra por sus próprios nombres, o al menos com nombres que encierem ideas analagas a los efectos uq produzem, há acordado y decreta. 
Art $1^{\circ}$ - Se proíbe bajo severa pena que desde hoy em adelante se llame bombardeo al que hace la escuarda brasileira: se llamará machacada si es de dia y si es de noche macaquiza. ${ }^{3}$

Aspectos críticos da luta são retratados em charges significativas e bem humoradas. O Exército Brasileiro é descrito como uma tartaruga, numa clara alusão à sua demora em marchar para a guerra. Em outra charge, a nossa tropa, totalmente negra, é derrotada por Lopez em seu sonho e D. Pedro II de joelhos pede clemência ao presidente paraguaio.

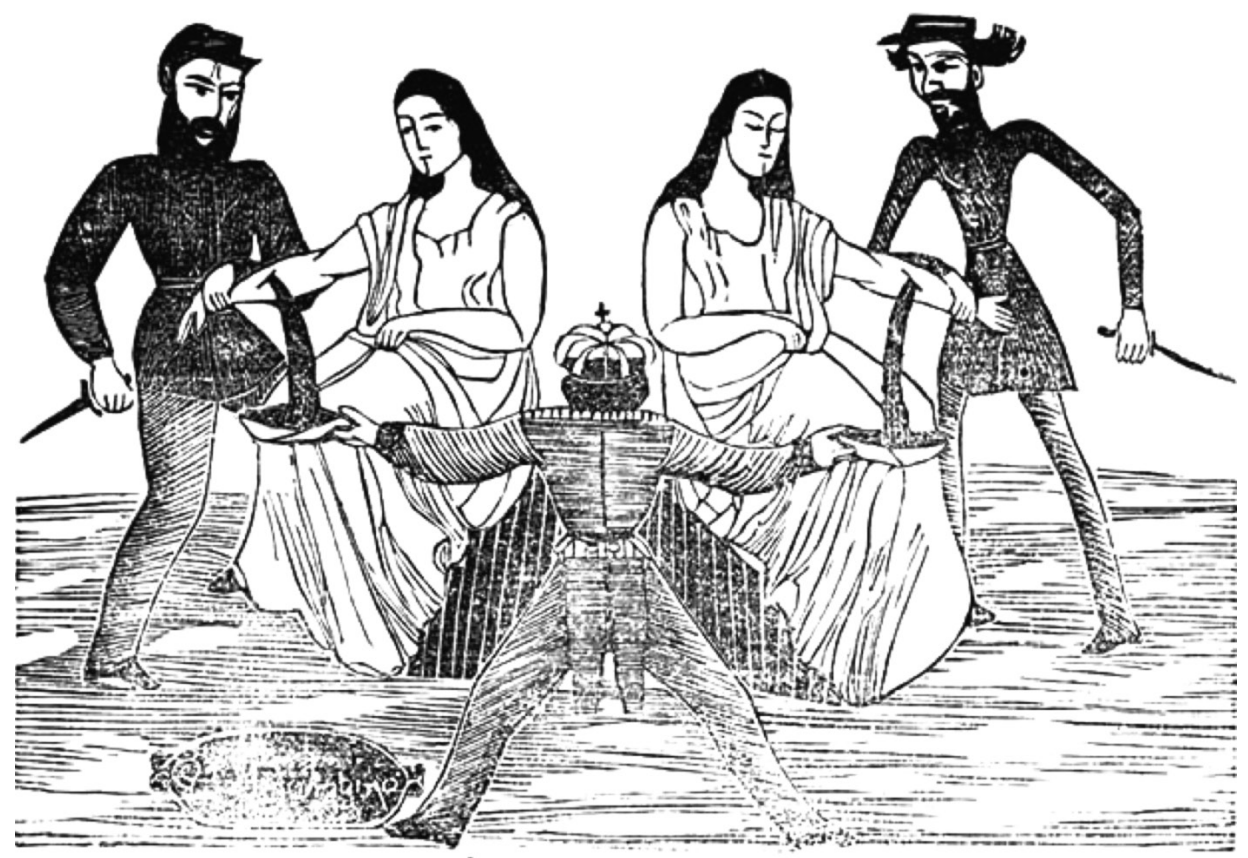

El Empcrador; ahran bem esas velan o alnda ha sangue.

Figura 6 - A representação da nação paraguaia sendo ultrajada pelo inimigo - Cabichuí - 1868

Tanto o Cabichuí quanto o El Centinela prosseguirão no bombardeio cômico do oponente, durante toda sua existência e circulação como periódico que durará até 1868, quando cai Assunção e torna inviável a confecção de jornais.

\footnotetext{
${ }^{3}$ CABICHUÍ, 1867: periódico de la guerra de la triple alianza. Edição facsimilar. Asunción: Museo del Barro. Página eletrônica: www.museodelbarro.com: acessado em 02/09/2011.
} 
O discurso e a desconstrução do inimigo continuaram, até o final de suas publicações, sem qualquer crítica ao governo paraguaio, mostrando o caráter tirânico e controlador do governo de Solano López sobre esses meios de comunicação.

Nesse sentido podemos diferenciar três grandes temas centrais nas produções paraguaias: nas primeiras fases da guerra que marcam a ofensiva paraguaia (1864/1865) e o contra-ataque aliado (1865/1866) as caricaturas paraguaias remetem a um exército de seres inferiores (macacos), incapazes de lutarem à altura do combatente guarani, na fase da estagnação (1866/1867), quando as tropas aliadas invadem o território Paraguai e não conseguem passar da linha fortificada de Humaitá, as tropas aliadas são descritas como lentas, inoperantes, de má pontaria, no entanto vencida Humaitá quando os aliados retomam a ofensiva (1868) as imagens irão remeter ao holocausto da nação, à escravidão que o será o futuro do Paraguai.

Interessante verificar que uma idéia que irá acompanhar toda produção dos jornais paraguaios no decorrer do conflito será a fragilidade da aliança Brasil, Argentina e Uruguai e a sombra monarquista e escravocrata do império brasileiro.

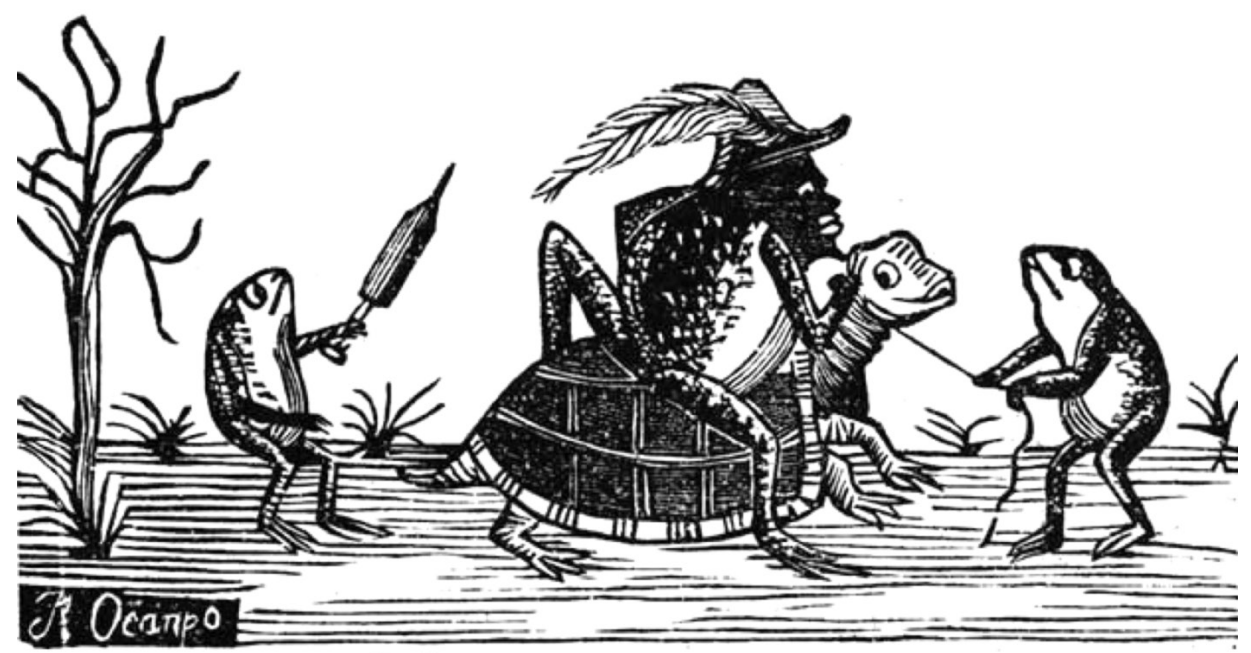

Caxias domando su nuevo Carumbé.

Figura 7 - A lentidão do exército aliado e a figura do Marquês - Cabichuí - 1868. 
Os acontecimentos militares geralmente são registrados por uma série de documentos, mas geralmente são captados valendo-se de um determinado ponto de vista, de maneira unilateral e incompleta.

Mesmo quando se oferecem de forma abundante, como é o caso da cobertura de um tema tão controverso e que afeta toda uma sociedade como a guerra, não se pode perder de vista sua subjetividade, implícita no seu registro a partir de um dado lugar, de uma dada época e de um olhar próprio de quem o produziu.

Todo documento é uma interpretação daquilo que ocorreu. Cabe ao historiador analisá-lo tendo essa premissa, criticá-lo, confrontá-lo com outras fontes, outras interpretações, perceber as nuances que o envolvem, sua confecção, seu discurso.

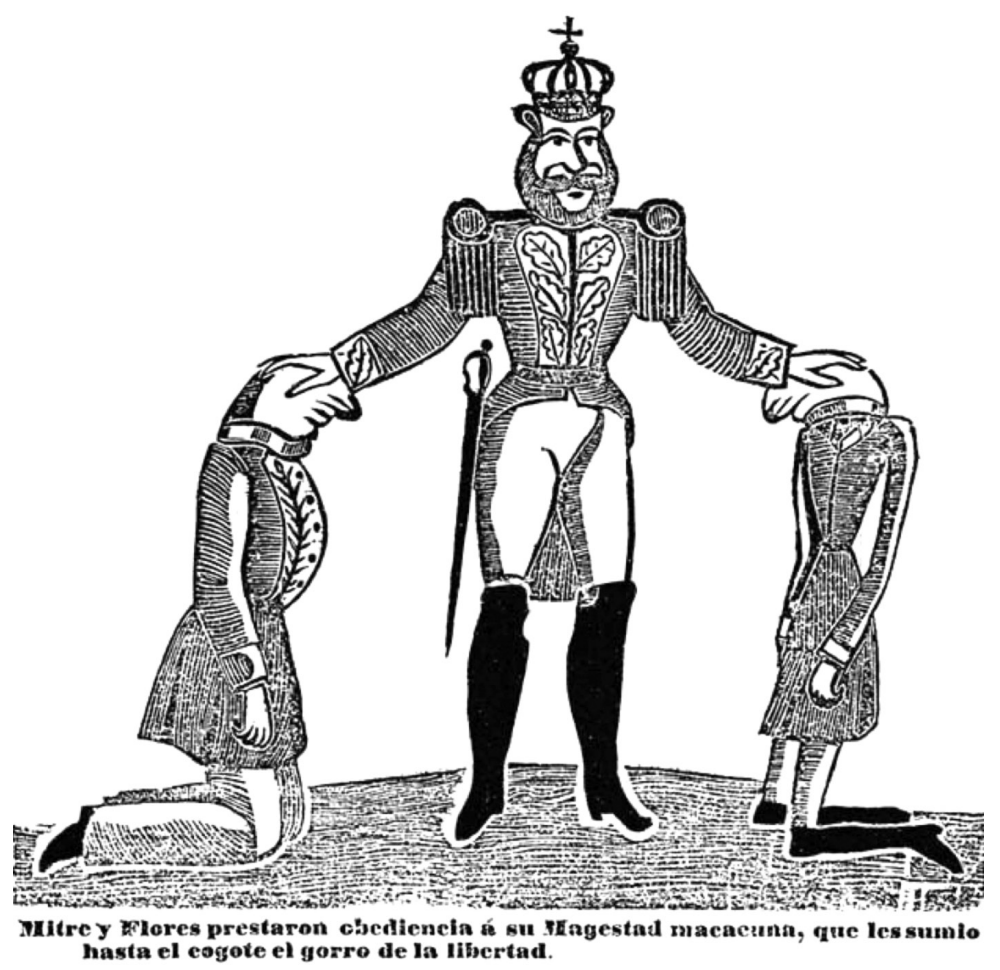

Figura 8 - a Tríplice Aliança sob os interesses do império - Cabichuí - 1867.

As caricaturas e charges produzidas à época ao revelarem um outro olhar sobre o real, um outro lado da história, sempre crítica, envolvendo um apelo a 
um outro sentido, mais ligado ao imaginário, não significou, necessariamente, que fora um agente de mudanças das práticas sociais, ao contrário, seu papel procurou evidenciar a manutenção da ordem vigente, especialmente através da criação de personagens estereotipados, validando preconceitos.

Essa práxis foi largamente utilizada por ambos os lados do conflito através da personificação do inimigo a ser vencido, animalizando-o, banalizando-o.

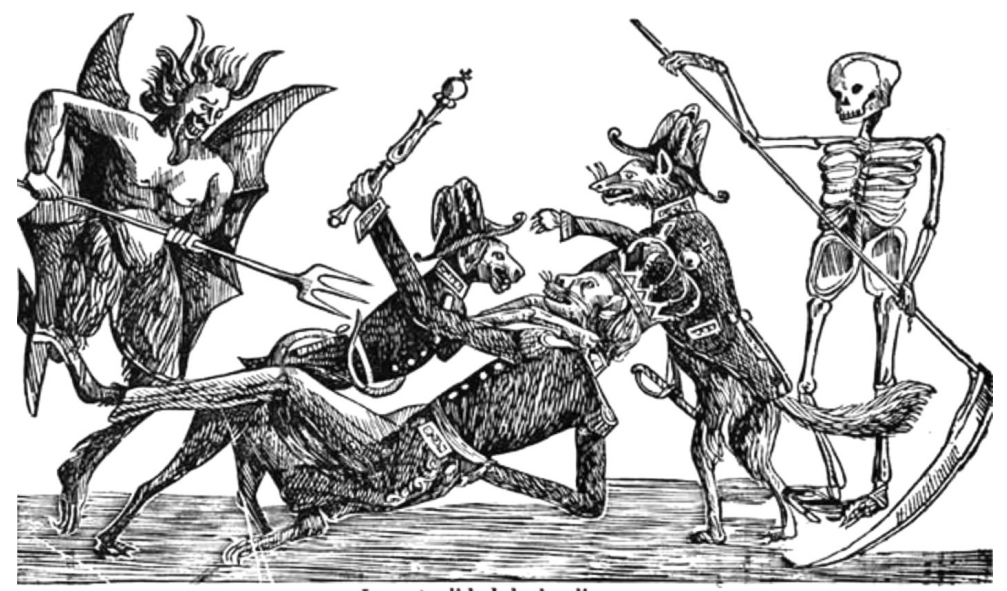

La actualidad de la alianza.

Figura 9 - As desavenças da Tríplice Aliança - El Centinela, 1868.

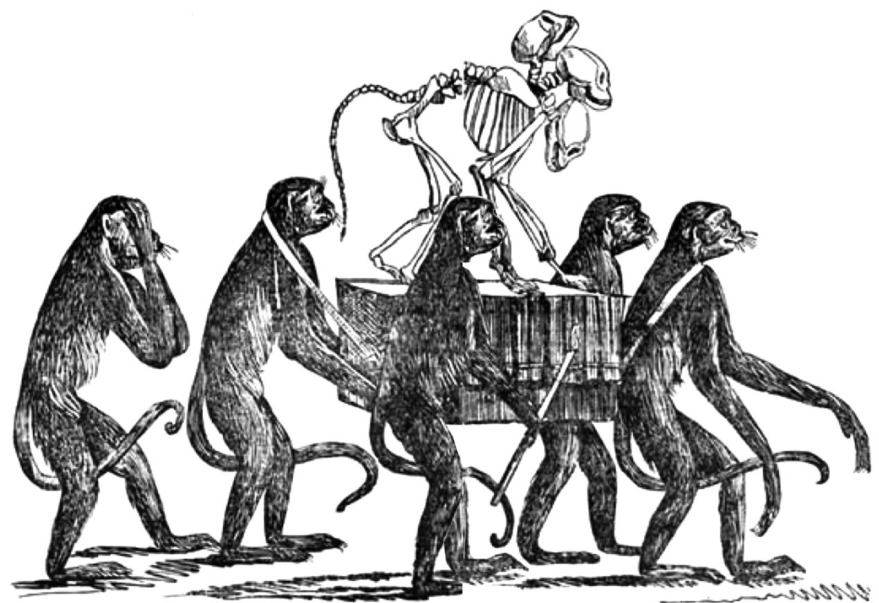

To hay siso una cera pan ese entioro, y̦ esta es la antore la verdad aue ilumina la marcha funcerria del conroi.

Figura 10 - Exército de macacos, carregando em marcha fúnebre os ossos da Aliança - El Centinela, 1867 
Os desenhos veiculados tanto nos periódicos paraguaios Cabichuí e El Centinela quanto nos da corte do Rio de Janeiro disseminaram e gravaram na memória, preconceitos até hoje perceptíveis nos países platinos. Essas caricaturas, esses discursos imagéticos contribuíram para consolidar estigmas, que revestem a Guerra da Tríplice Aliança ou Guerra do Paraguai de importante atualidade.

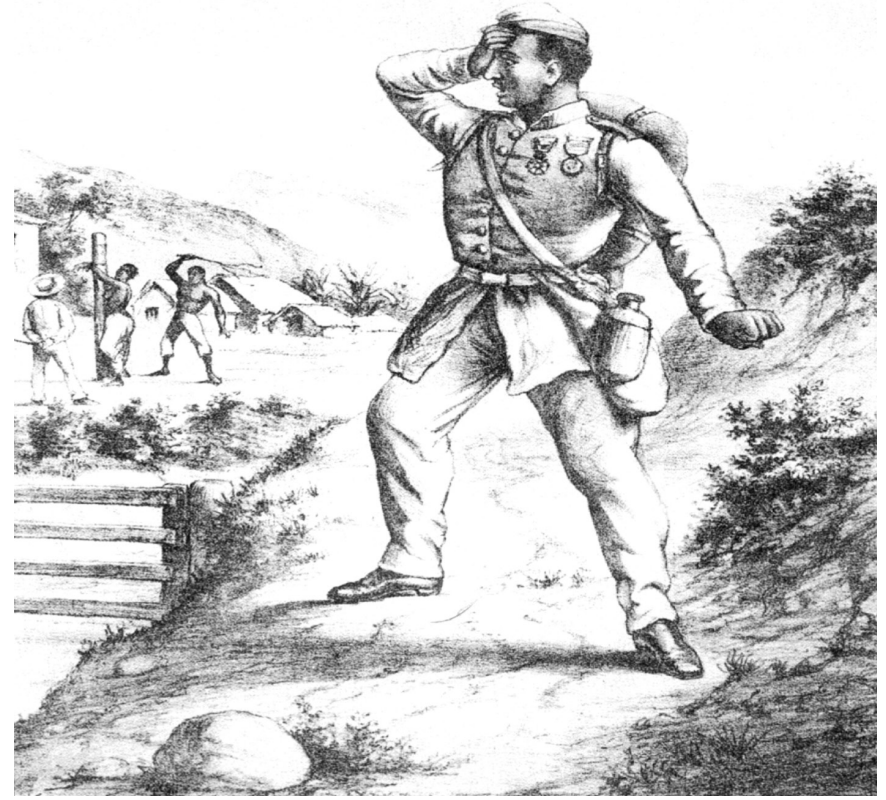

Figura 11 - O retorno da soldado negro, herói de guerra à monarquia escravocrata - A Vida Fluminense - 1870.

O imaginário é composto de imagens que transmitem a idéia, opinião, imaginação de quem as criou sob efeito de várias influências: sociais, culturais, afetivas. O preconceito não é só o que se mostra, mas principalmente o que se esconde, o que se mascara, gravado no interior, na memória; difícil de se dissociar do que o ser humano é.

O tema guerra e toda suas possibilidades potencializaram certas práticas que, na intenção de auxiliarem como motivação de combate no esforço dos estados num conflito de alguns anos, sedimentaram e perduraram certas idéias-imagens por séculos, sendo hoje em dia, mais um dificultador da tão sonhada integração regional. 


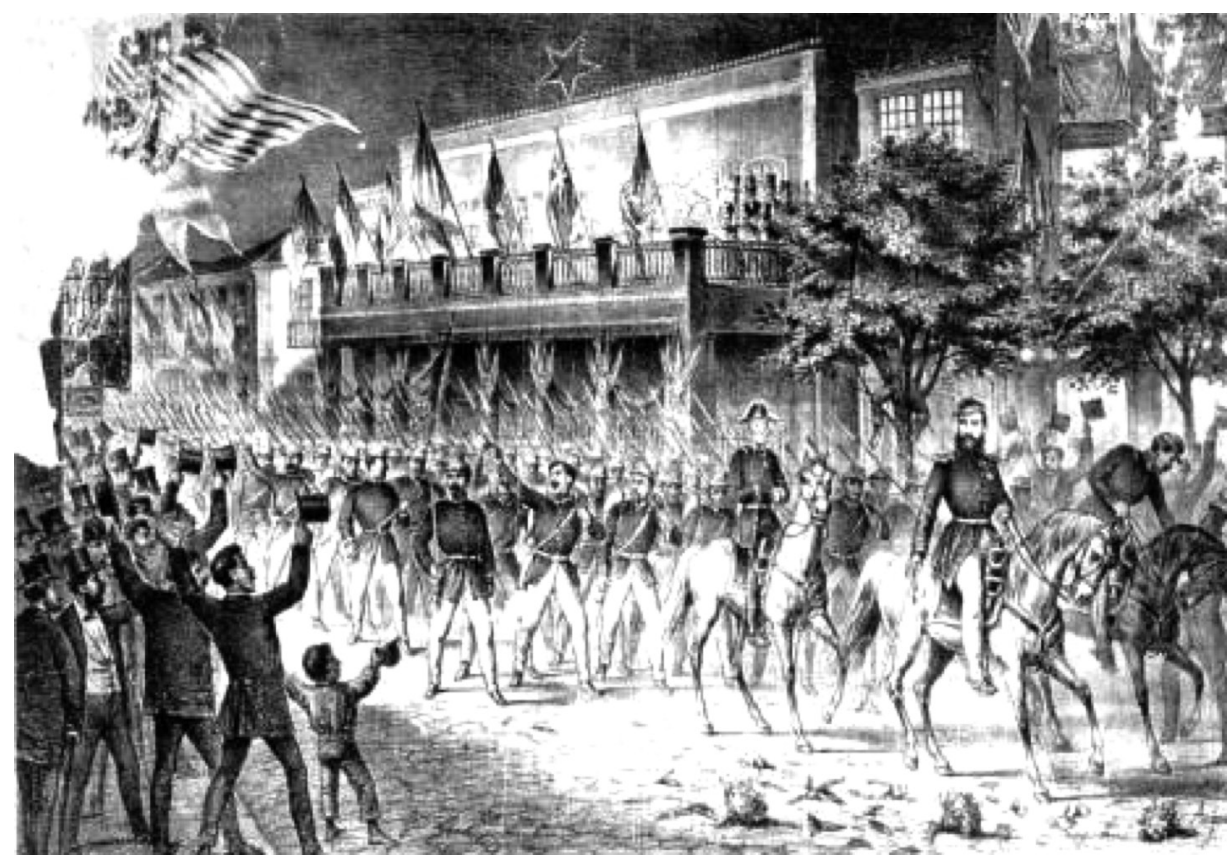

Figura 12 - Retorno triunfal das tropas imperiais - A Vida Fluminense - 1870.

Podemos então nos perguntar: Por que e para que esse revisitar? Qual seria a utilidade prática (para sermos bem atuais) nesses estudos desse tão longínquo oitocentos? Devemos comemorar nossa vitórias? Envergonharmos de nossas derrotas? Ou o contrário, devemos envergonharmos de nossas vitórias?

Bem, acreditamos que esse olhar menos apologético da história, particularmente, da história militar, possa colocar esses homens e mulheres que viveram e morreram nessa grande guerra em sua real dimensão, na sua época, no seu lugar, para que a partir daí, talvez, entendendo-os em suas fraquezas, em seus altruísmos, em suas humanidades, em seus "lugares de fala", através do conhecimento, fazermos todos juntos, brasileiros, paraguaios, argentinos e uruguaios, uma "catarze" intelectual e construímos, juntos, um futuro melhor, uma História que não separa, antes aproxima. 


\section{Principais Fontes Imagéticas}

\section{Periódicos paraguaios}

Cabichuí: periódico de la guerra de la triple alianza. Edição facsimilar. Asunción: Museo del Barro. Página eletrônica: www.museodelbarro.com

El Centinela: periódico de la guerra de la triple alianza. Edição facsimilar. Asunción: Centro de Artes Visuales - Museo del Barro. Página eletrônica: www.museodelbarro.com

\section{Periódicos brasileiros}

Semana Illustrada: Biblioteca Nacional. Loc. Título PR-SOR 02334 (1-8). Período microfilmado: $16 \mathrm{dez}$ 1860/19 mar 1876

Paraguay Illustrado: Biblioteca Nacional. Loc. Título PR-SOR 02153. Período microfilmado: $30 \mathrm{jul} / 26$ out 1865

Bazar Volante: Biblioteca Nacional. Loc. Título PR-SOR 02148. Período microfilmado: out 1865/ dez 1866 (sucedido por: O Arlequim)

O Arlequim: Biblioteca Nacional. Loc. Título PR-SOR 02145. Período Microfilmado: 5 mai/ 29 dez 1867 (sucedido por: A Vida Fluminense)

A Vida Fluminense: Biblioteca Nacional. Loc. Título PR-SOR 02154. Período microfilmado: 4 jan 1868/ 25 dez 1875 